\title{
Effects of Abscisic Acid Treatment on Berry Coloration and Expression of Flavonoid Biosynthesis Genes in Grape
}

\author{
Ayako Katayama-Ikegami ${ }^{*}$, Tomoaki Sakamoto1, Kana Shibuya1, Takane Katayama ${ }^{1,2}$, \\ Mei Gao-Takai ${ }^{1}$ \\ ${ }^{1}$ Faculty of Bioresources and Environmental Sciences, Ishikawa Prefectural University, Ishikawa, Japan \\ ${ }^{2}$ Graduate School of Biostudies, Kyoto University, Kyoto, Japan \\ Email: "aikegami@ishikawa-pu.ac.jp
}

Received 19 March 2016; accepted 15 July 2016; published 18 July 2016

Copyright @ 2016 by authors and Scientific Research Publishing Inc.

This work is licensed under the Creative Commons Attribution International License (CC BY).

http://creativecommons.org/licenses/by/4.0/

(c) () O) Open Access

\begin{abstract}
In order to enhance berry coloration of bright-red grape cultivars, the effects of abscisic acid (ABA) treatment on the quantity and composition of anthocyanins as well as the expression of genes related to flavonoid biosynthesis in the berry were examined. Exogenous ABA treatment increased anthocyanin content, especially petunidin- and malvidin-type anthocyanins. Quantitative realtime PCR analysis revealed that ABA treatment around véraison resulted in the upregulation of genes encoding enzymes responsible for both general flavonoid and anthocyanin biosynthesis. On the other hand, the gene expressions of enzymes involved in proanthocyanidin synthesis were drastically decreased at véraison and remained extremely low even with ABA treatment. Thus, increases in the total amount and composition ratios of petunidin- and malvidin-type anthocyanins were mainly caused by ABA-induced upregulation of uridine diphosphate glucose flavonoid glucosyl transferase, glutathione S-transferase 4, O-methyl transferase and flavonoid 3', 5' hydroxylase expression, resulting in the deep coloration of berry of skin.
\end{abstract}

\section{Keywords}

Abscisic Acid (ABA), Anthocyanin, Biosynthetic Enzyme, Gene Expression, Transcription Factor

\section{Introduction}

The color of grape berry is determined by the quantity and composition of anthocyanins [1]-[3], which belong to

${ }^{*}$ Corresponding author.

How to cite this paper: Katayama-Ikegami, A., Sakamoto, T., Shibuya, K., Katayama, T. and Gao-Takai, M. (2016) Effects of Abscisic Acid Treatment on Berry Coloration and Expression of Flavonoid Biosynthesis Genes in Grape. American Journal of Plant Sciences, 7, 1325-1336. http://dx.doi.org/10.4236/ajps.2016.79127 
the class of flavonoid molecules that are synthesized via the phenylpropanoid pathway (Figure 1). Two classes of genes are required for anthocyanin biosynthesis; one includes structural genes encoding enzymes that directly participate in the formation of anthocyanins and other flavonoids, and the other comprises regulatory genes controlling the transcription of structural genes. Uridine diphosphate-D-glucose: flavonoid 3-O-glucosyltransferase (UFGT) is a key enzyme determining carbon flow to anthocyanins, and its expression is regulated by myeloblastosis (Myb)-related transcription factors (VvMybA and VlMybAs) [4]-[7]. Additionally, VvMyb5a and VvMyb5b regulate the expression of enzymes involved in both anthocyanin and proanthocyanidin biosynthesis [8]-[10], while VvMybPA1 [11] [12], VvMybPA2 [13], VvMybPAR [14] and VvMybF [15] regulate the expression of enzymes responsible for proanthocyanidin and flavonol biosynthesis. Anthocyanidin reductase (ANR), which catalyzes the production of the building blocks of proanthocyanidins, competes with UFGT as one of the key enzymes that modulate carbon flow to proanthocyanidins [16]. Synthesized anthocyanins are sequestered in vacuoles by the non-enzymatic flavonoid carrier protein glutathione $S$-transferase (GSTs) and tonoplast-localized multidrug and toxic compound extrusion family transporters such as AnthoMATE [17]-[19].

Various environmental and physiological factors affect anthocyanin biosynthesis and grape coloration [20] [21]. Anthocyanins accumulate in grape skin after véraison, the onset of ripening in non-climacteric fruit,

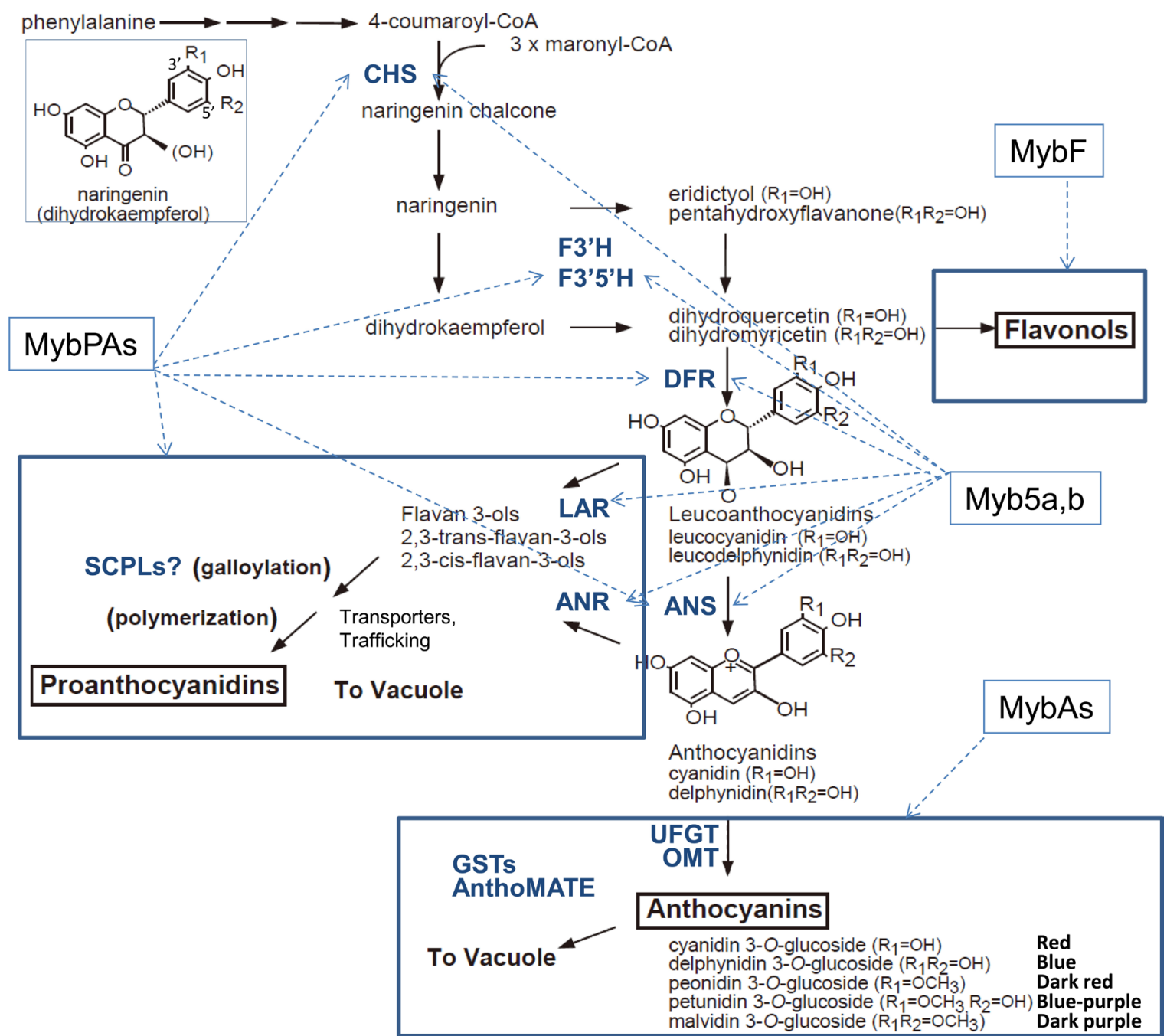

Figure 1. Principal pathway of flavonid biosynthesis and related Myb transcription factors in grape. ANR, anthocyanidin reductase; ANS, anthocyanidin synthase; anthoMATE, anthocyanin multidrug and toxic compound extrusion family transporters; CHS, chalcone synthase; DFR, dihydroflavonol reductase; F3'H, flavonoid 3'-hydroxylase; F3',5'H, flavonoid 3',5'-hydroxylase; GST, glutathione $S$-transferase; OMT, flavonoid $O$-methyltransferase; SCPL, serine carboxipeptidase-like acyltransferase; UFGT, flavonoid 3-O-glucosyltransferase. 
when grape berry maturation is accompanied by an increase in deformability and sugar content and decrease in acidity [22] [23]. These changes are regulated by physiological factors such as sugar accumulation and plant hormone levels [21]. This process is assumed to be triggered by endogenous abscisic acid (ABA), the level of which increases starting from the initial stage of fruit ripening and remains transiently elevated after véraison [21]. ABA application to grape clusters [21] [24] [25] and cell cultures [26] [27] is known to enhance anthocyanin accumulation via activation of the anthocyanin biosynthesis pathway. Therefore, ABA is a good candidate plant growth regulator for controlling the development of skin color in grapes. Here, we report the effects of ABA treatment on the quantity and composition of anthocyanins as well as the expression of genes related to anthocyanin biosynthesis, in order to develop the method for improving the coloration of a red grape berry variety. Our results suggest that the factor(s) other than ABA may also be involved in determining the carbon flow of flavonoid synthesis, especially proanthocyanidin biosynthesis, during grape berry development.

\section{Materials and Methods}

\subsection{Plant Materials and ABA Treatment}

One 25-year-old “Aki Queen” grape (Vitis vinifera $\times$ Vitis labruscana) grown at the Experimental Farm of Ishikawa Prefectural University was used for the treatment. Full-bloom clusters were dipped in 25 ppm gibberellic $\operatorname{acid}_{3}\left(\mathrm{GA}_{3}\right)$ solution including $5 \mathrm{ppm}$ forchlorfenuron for inducing seedless, then dipped again in the same solution without forchlorfenuron 10 days after full-bloom (DAF), to stimulate berry growth. Clusters were sprayed with 200 or 400 ppm ABA solution (about 6 ml; BAL Planning Co., Japan) at 39, 48, or 55 days after full-bloom (DAF) based on our previous research (unpublished data). Véraison occurred around 42 DAF and clusters were harvested at 83 DAF. For all experiments, control clusters received no ABA treatment and there were eight replicates for each treatment.

\subsection{Analysis of Total Soluble Solids (TSS) and Titratable Acidity}

The pulp of peeled berries was squeezed and TSS and titratable acidity of the juice were determined. TSS content was measured with a digital refractometer (PAL-1; Atago Co., Japan). Titratable acidity was determined by titration and is expressed as the mass (in grams) of tartaric acid equivalent per $100 \mathrm{ml}$ of juice. The significance of differences in TSS and titratable acidity between samples was determined using Tukey's test.

\subsection{Analysis of Anthocyanin Content and Composition}

Anthocyanins were extracted from $200 \mathrm{mg}$ of freeze-dried berry skin in $15 \mathrm{ml}$ of $50 \%(\mathrm{v} / \mathrm{v})$ acetic acid at $4^{\circ} \mathrm{C}$ for $24 \mathrm{~h}$ according to previously reported [28]. Total anthocyanin content was measured at $520 \mathrm{~nm}$ using a spectrophotometer (Biospec-1600; Shimadzu, Japan). For high-performance liquid chromatography (HPLC) analysis, the extract was passed through a $0.45-\mu \mathrm{m}$ filter, and samples were subjected to reverse-phase HPLC using a Prominence LC20A instrument (Shimadzu, Japan) with a C18 Inertsil ODS-2 analytical column (5 $\mu \mathrm{m}, 250 \times$ $6.0 \mathrm{~mm}$ inner diameter; GL Sciences, Japan) protected by a guard column containing the same material as previously reported [28]. Analysis was carried out at $35^{\circ} \mathrm{C}$, with mobile phase flow at $0.8 \mathrm{ml} \cdot \mathrm{min}^{-1}$. Elution was carried out with solvent A [1.5\% (v/v) phosphoric acid] followed by solvent B [1.5\% (v/v) phosphoric acid, 20\% (v/v) acetic acid, and $25 \%(\mathrm{v} / \mathrm{v})$ acetonitrile]. The concentration of solvent B was linearly increased from $25 \%$ to $85 \%$ over 40 min. Peaks detected by HPLC were identified by comparing the retention time and elution order of the standards cyanidin-3-monoglucoside (Cy3G), peonidin-3-monoglucoside (Pn3G), delphinidin-3-monoglucoside (Dp3G), petunidin-3-monoglucoside (Pt3G), and malvidin-3-monoglucoside (Mv3G). The other constituents, peonidin-3,5-diglucoside (Pn35G), cyanidin-3-( $p$-coumarylglucoside)-5-glucoside (Cy3pG5G), delphinidin-3-p-coumarylglucoside (Dp3pG), peonidin-3-(p-coumarylglucoside)-5-glucoside (Pn3pG5G), malvidin-3( $p$-coumarylglucoside)-5-glucoside (Mv3pG5G), cyanidin-3-p-coumarylglucoside (Cy3pG), petunidin-3-p-coumarylglucoside (Pt3pG), peonidin-3-p-coumarylglucoside (Pn3pG), and malvidin-3-p-coumarylglucoside (Mv3pG) were estimated comparing the retention time and elution order as previously described [2] [28]. The concentration of each anthocyanin group, cyanidin (Cy3G, Cy3pG5G and Cy3pG), peonidin (Pn3G, Pn35G, Pn3pG5G and Pn3pG), delphinidin (Dp3G and Dp3pG), petunidin (Pt3G and Pt3pG), and malvidin (Mv3G, Mv3pG5G and $\mathrm{Mv3pG}$ ), was calculated based on peak areas and calibration curves of Cy3G, Pn3G, Dp3G, Pt3G and Mv3G, respectively. The significance of differences in anthocyanin concentration and composition between 
samples was determined using Student's t-test for concentration and Tukey’s test for composition

\subsection{Gene Expression Analysis}

Total RNA was extracted from $400 \mathrm{mg}$ of berry skin using the hot borate method [29]. After treatment with DNaseA (Thermo Scientific, USA), single-stranded cDNA was synthesized using SuperScript III Reverse Transcriptase (Invitrogen, USA) in the presence of RNasin ribonuclease inhibitor (Promega, USA) and an oligo-dT primer. Quantitative real-time (qRT-)PCR was carried out with the StepOnePlus Real-Time PCR System (Applied Biosystems, USA) and the SYBR Green system with SYBR Pre-mix Ex-Taq II (Takara Bio, Japan). Primer sequences are listed in Table 1. The primer sets for chalcone synthase 3 (CHS3) and open stomata (OST)1 were prepared (synthesized) based on the previous reports [24] [30]. The amplification protocol was as follows: $95^{\circ} \mathrm{C}$ for $30 \mathrm{~s}$, followed by 45 cycles of $95^{\circ} \mathrm{C}$ for $5 \mathrm{~s}$ and $60^{\circ} \mathrm{C}$ for $30 \mathrm{~s}$. The specific amplification of target genes was verified by polyacrylamide gel electrophoresis. Expression levels were normalized to that of glyceraldehyde 3-phosphate dehydrogenase, which was used as the internal reference. OST1 [30] and Chitinase (CHT)4 [31] were used as reporter genes for the ABA signal. Three independent RNA extractions were used for the analyses. All PCR reactions were replicated twice with the same cDNA samples and Student's $t$-test was used to determine significant differences in expression between the means.

Table 1. Sequences of the primers used in gene expression analysis.

\begin{tabular}{|c|c|c|c|}
\hline Gene & Forward $\left(5^{\prime} \rightarrow 3^{\prime}\right)$ & Reverse $\left(5^{\prime} \rightarrow 3^{\prime}\right)$ & Accession no. \\
\hline \multicolumn{4}{|c|}{ Transcription factors } \\
\hline VlMybA1-2 & AGCCTGTTAGCTGAGCTGGA & CCTCCCTGGATTTGTTCGAT & AB073012 \\
\hline VlMybA1-3 & CTGAGCATACTCAAATGGATCAAG & CACCTCCCTGGATTTGTTCTAC & AB427165 \\
\hline VlMybA3 & CAAAGCTATAAAGTCTCGCAAGC & CACCTCCCTGGATTTGTTCTAC & FJ687580 \\
\hline MybPA1 & TCGGAGATGATCAAGGTCAAGA & CGCTCAAGCAGTTGCAGATACT & NM_001281231 \\
\hline MybPA2 & CCGTCTCCTAAAATGGCAGTTC & ATGAAAGAATTGGCGGTTTCG & NM_001281024 \\
\hline Myb5a & AGCAACGATGACGAAGACGAT & AGGGAACACATCCTCATTGATC & NM_001281179 \\
\hline$M y b 5 b$ & ACCGATGATGTCTTCTCTTCATTTT & ACCATGGTGCTGTTGTTGGA & NM_001280925 \\
\hline \multicolumn{4}{|l|}{ Enzymes } \\
\hline CHS3 & TCGGCTGAGGAAGGGCTGAA & GGCAAGTAAAGTGGAAACAG & - \\
\hline DFR & CAAGAACACCAACTGCCAGTGT & GCCCGGCAAAATTCCATAT & NM_001281215 \\
\hline ANS & GGCCTCAGGTTCCAACTATTGA & CAACTCCTCCCGGCATCTC & NM_001281218 \\
\hline$F 3^{\prime} H$ & AGGCAAGCTCACCGACGTT & CTGTGCTGGATGAGGTGTCAGT & АВ213603 \\
\hline$F 3^{\prime}{ }^{\prime} H$ & AACCCAGATTTTCTGGACGTAA & GCAGTAAATAAATTCAGGAGGAGTG & XM_010653221 \\
\hline$U F G T$ & AAGCCGGGTACCGTTTATATG & CAACTGCCTCATGTGCTAGG & AB047091 \\
\hline FaOMT & TGAGAGAGCAGGCAGAGTCC & CGCGACGCCATCTCCAATAG & HM142924 \\
\hline ANR & TGCGACTTTGTCTTCCATGTTG & ATTGCTGGCTTGATCATGTCAT & NM_001280956 \\
\hline SCPL7 & GCTTCCCATCTTACACAGAAAATGT & CAAAGCCCGGAGACCTGTT & XM_002269403 \\
\hline SCPL16 & GTGCCGGAACTTCAATTATGC & CCACTCGGACATTTAATGCTTCT & XM_002272080 \\
\hline \multicolumn{4}{|c|}{ Carrier and transporters } \\
\hline GST4 & GGAGGAGAAAGCGGTAGTTGATC & GCATGACCAGTGTGTACACCAA & NM_001280940 \\
\hline AM1 & ATCGGTTGGTGCAAAGAAGG & ATCTCTAGGCAAAGCATCACAGC & NM_001303078 \\
\hline \multicolumn{4}{|l|}{ ABA response } \\
\hline CHT4 & TCAAGTAGCGGCAGTGGTAGC & GGCACTGAGAAACGCTGCAC & NM_001281146 \\
\hline OST1 & GCAACGCTGGTCGGTTTAGT & TAAGCCGTGGCATTGGACTT & - \\
\hline \multicolumn{4}{|l|}{ Reference } \\
\hline GADPH & CCAAGGCTGGAATAGCACTC & CCATGTGGACAATCAAGTCG & XM_002263109 \\
\hline
\end{tabular}




\section{Results}

\subsection{ABA Treatment Enhances Anthocyanin Accumulation and Berry Coloration}

ABA treatment enhanced berry coloration (Figure 2). In the 39 DAF treatment group, 400 ppm ABA increased total anthocyanin content, whereas 200 and 400 ppm ABA decreased TSS (Table 2). Similar results were observed for the 48 DAF treatment group. In the 55 DAF group, ABA concentrations of 200 and 400 ppm increased total anthocyanin content while $400 \mathrm{ppm}$ decreased TSS. In these experiments, anthocyanin accumulation was more effectively induced by treatment with 400 ppm than 200 ppm ABA; in the 55 DAF treatment, total anthocyanin content was increased 5 fold relative to untreated berry skin by $400 \mathrm{ppm}$ ABA. Titratable acidity was affected by application of only $200 \mathrm{ppm}$ ABA at 39 DAF (Table 2).

The amounts and composition ratios of various anthocyanin groups were examined by HPLC analysis (Figure 3). Exogenous ABA treatment stimulated accumulation of all type of anthocyanins in the berry skin. Interestingly, irrespective of the timing of treatment, the concentrations of petunidin- and malvidin-type anthocyanins, which are synthesized through the actions of flavonoid 3',5' hydroxylase (F3'5' $\mathrm{H})$ and flavonoid 3',5' $O$-methyltransferase (FaOMT), were significantly increased. In contrast, the composition ratios of cyanidin and peonidin group were decreased while their amounts were increased by ABA treatment; consequently, the composition ratios of both groups became lower than the control value ( $<50 \%$ vs. $74 \%)(P<0.05)$.

\subsection{ABA Treatment Differently Modulates Myb Transcription Factors Involved in Anthocyanin Biosynthesis}

qRT-PCR analysis was carried out using cDNA prepared from berry skin without treatment (control) or treated with 400 ppm ABA at 39 DAF. Consistent with previous reports that endogenous ABA content increased after véraison [22] [23], the expression level of the ABA-responsive gene CHT4 [30] was increased in control berry skin about 2 weeks after véraison (at 54 DAF, Figure 4). CHT4 expression level in ABA treated berry skin was

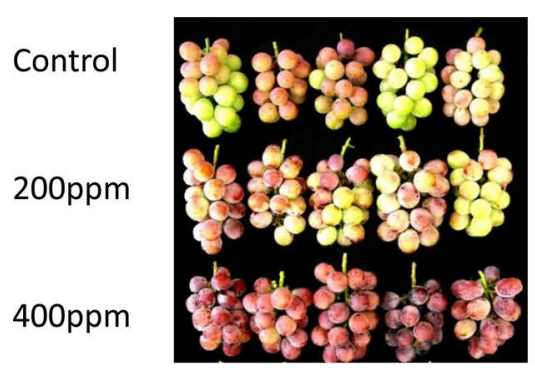

39 DAF

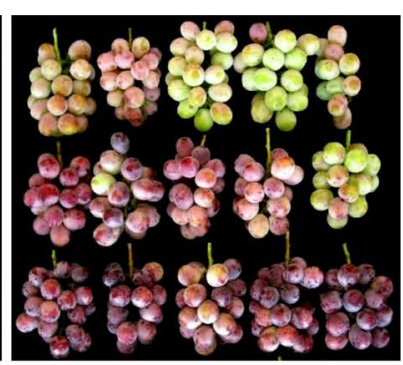

48 DAF

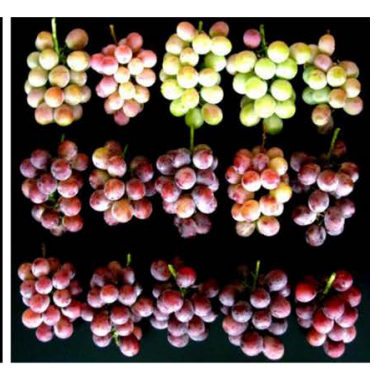

55 DAF

Figure 2. Effects of ABA treatment on color development of “Aki Queen” grape berries. Clusters were treated with 200 or $400 \mathrm{ppm} \mathrm{ABA}$ at 39,48 , or $55 \mathrm{DAF}$ and harvested at $83 \mathrm{DAF}$.

Table 2. Effects of ABA treatments on total anthocyanin contents, TSS and titratable acidity.

\begin{tabular}{ccccc}
\hline Timing of treatment & ABA concentration & Anthocyanin $\left(\mathrm{OD}_{520}\right)$ & TSS $\left({ }^{\circ}\right.$ Brix $)$ & Titratable acidity $\left(\mathrm{g} 100 \mathrm{ml}^{-1}\right)$ \\
\hline \multirow{2}{*}{$39 \mathrm{DAF}$} & control & $0.63 \pm 0.27 \mathrm{~b}^{*}$ & $18.38 \pm 0.75 \mathrm{a}$ & $0.37 \pm 0.05 \mathrm{~b}$ \\
& $200 \mathrm{ppm}$ & $0.80 \pm 0.30 \mathrm{~b}$ & $16.52 \pm 0.07 \mathrm{~b}$ & $0.44 \pm 0.02 \mathrm{a}$ \\
& $400 \mathrm{ppm}$ & $1.68 \pm 0.44 \mathrm{a}$ & $16.74 \pm 0.28 \mathrm{~b}$ & $0.38 \pm 0.02 \mathrm{ab}$ \\
\multirow{2}{*}{$48 \mathrm{DAF}$} & control & $0.63 \pm 0.27 \mathrm{~b}$ & $18.38 \pm 0.75 \mathrm{a}$ & $0.37 \pm 0.05$ \\
& $200 \mathrm{ppm}$ & $1.06 \pm 0.29 \mathrm{~b}$ & $17.18 \pm 0.48 \mathrm{~b}$ & $0.38 \pm 0.04$ \\
& $400 \mathrm{ppm}$ & $2.44 \pm 0.44 \mathrm{a}$ & $16.68 \pm 0.06 \mathrm{~b}$ & $0.36 \pm 0.02$ \\
& control & $0.63 \pm 0.27 \mathrm{~b}$ & $18.38 \pm 0.75 \mathrm{a}$ & $0.37 \pm 0.05$ \\
& $200 \mathrm{ppm}$ & $2.40 \pm 0.06 \mathrm{a}$ & $17.76 \pm 0.95 \mathrm{a}$ & $0.39 \pm 0.03$ \\
\hline
\end{tabular}

${ }^{*}$ Values represent means \pm SD of 3 replicates for anthocyanin and 5 replicates for TSS and titratable acidity. Data followed by different letters (a, b) in each column differ significantly by the Tukey's test $(P \leq 0.05)$. 

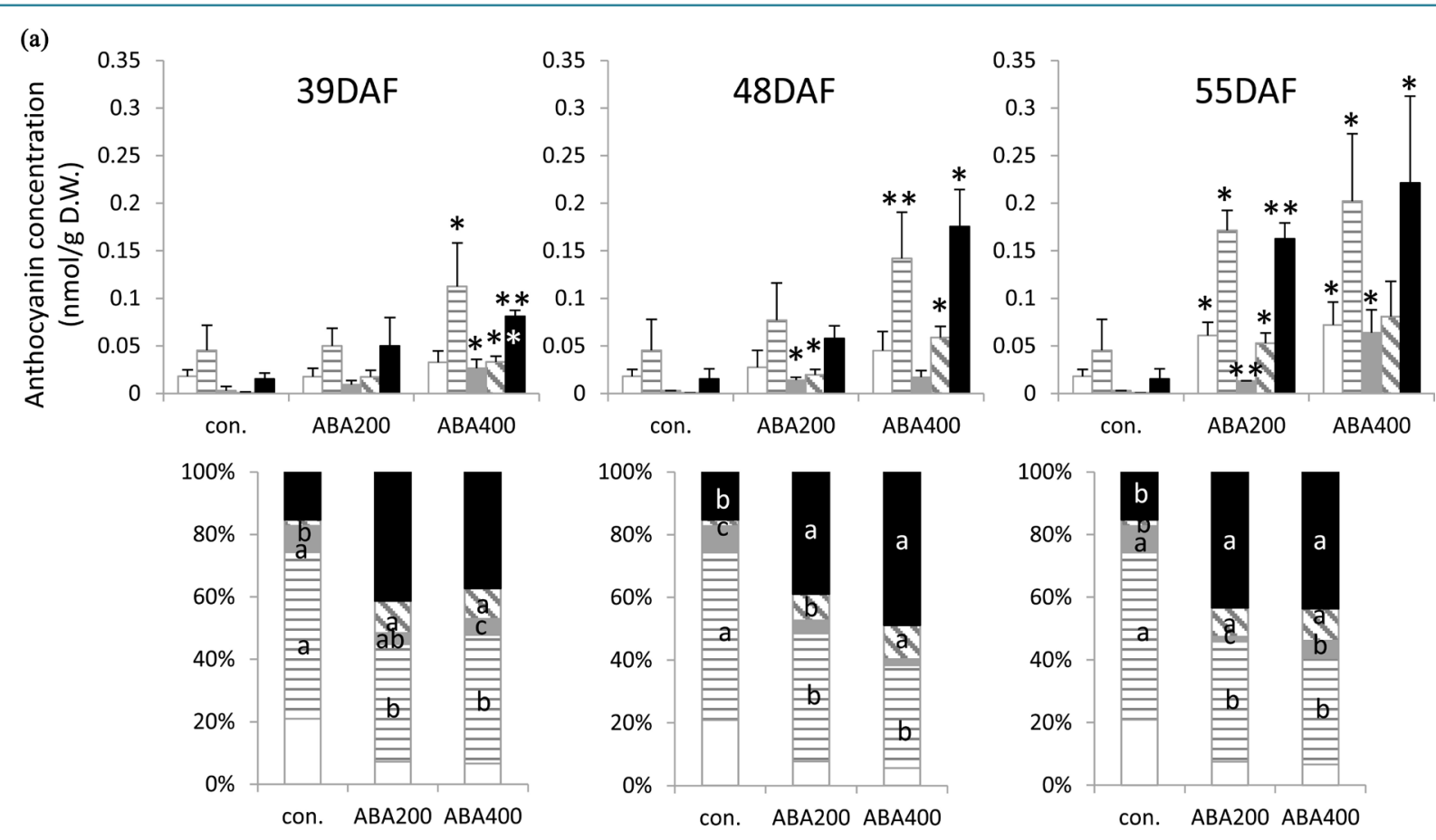

(b)
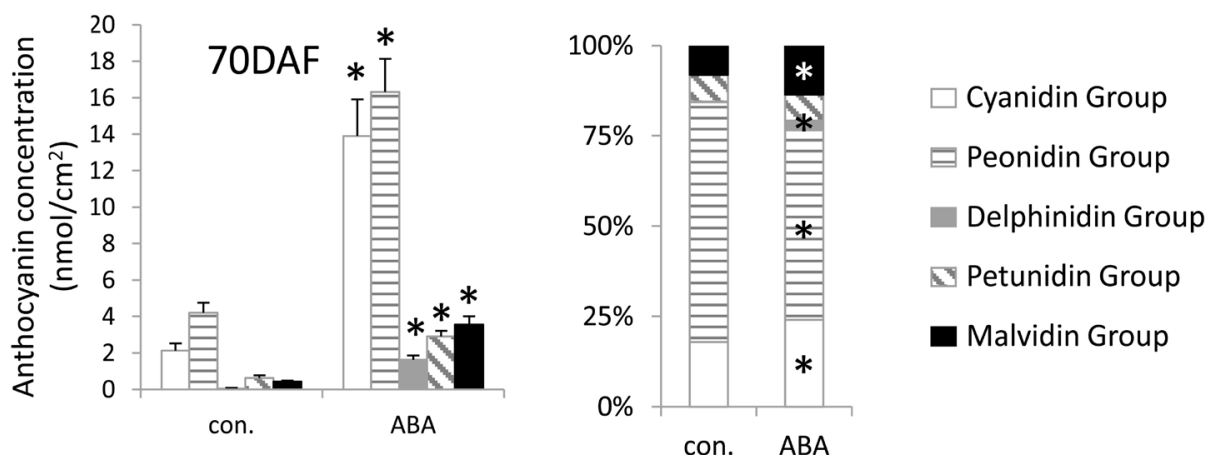

Figure 3. Effects of ABA treatment on the amounts and composition ratios of anthocyanin groups in "Aki Queen” grape berries. Clusters were treated with 200 or 400 ppm ABA at 39, 48, or 55 DAF and harvested at 83 DAF Stars indicate significance between treatment group $\left({ }^{*} P \leq 0.05,{ }^{* * *} P \leq 0.01, \mathrm{n}=3\right.$, Student's $t$-test).”, as second sentence. Bars labelled with different lower-case letters indicate significance differences between treatment groups $(P \leq 0.05, n=3$, Tukey's test).

increased by 6 fold relative to the level in untreated within 3 days (at 42 DAF), after which the magnitude of the difference decreased (to 3-fold higher than in the control at 54 DAF). The expression level of OST1, another ABA-responsive gene, was higher before véraison (at 27 and 33 DAF), and decreased thereafter (Figure 4) in control berry skin. OST1 expression was slightly increased by ABA treatment to 1.5 times the level in untreated berry skin within 3 days (at $42 \mathrm{DAF}$ ) and further increased to 3-fold higher at 54 DAF.

The qRT-PCR analysis revealed that all seven Myb-related transcription factor genes examined were expressed at different levels in control berry skin (Figure 4). Myb5a, Myb5b, MybPA1, and MybPA2 were expressed at higher levels before véraison and decreased gradually thereafter, with kinetics that was similar to those of OST1. In contrast, VIMybA1-2, VIMybA1-3, and MybA3 levels were slightly higher after véraison, with kinetics that were similar to those of $C H T 4$.

ABA treatment at least transiently increased Myb transcription factor gene expression, albeit to different degrees for each gene. For instance, Myb5a and Myb5b levels increased within 3 days of ABA treatment (at 42 DAF) to 1.6 and 1.5 times those in untreated berry skin, respectively, but were comparable to control levels at 54 DAF. On the other hand, MybPA1 and MybPA2 expression was 2.1 and 3.3 times higher, respectively, at 42 DAF and 4.3 and 2.1 times higher, respectively, at 54 DAF than the levels in untreated berry skin. VIMybA1-2, 


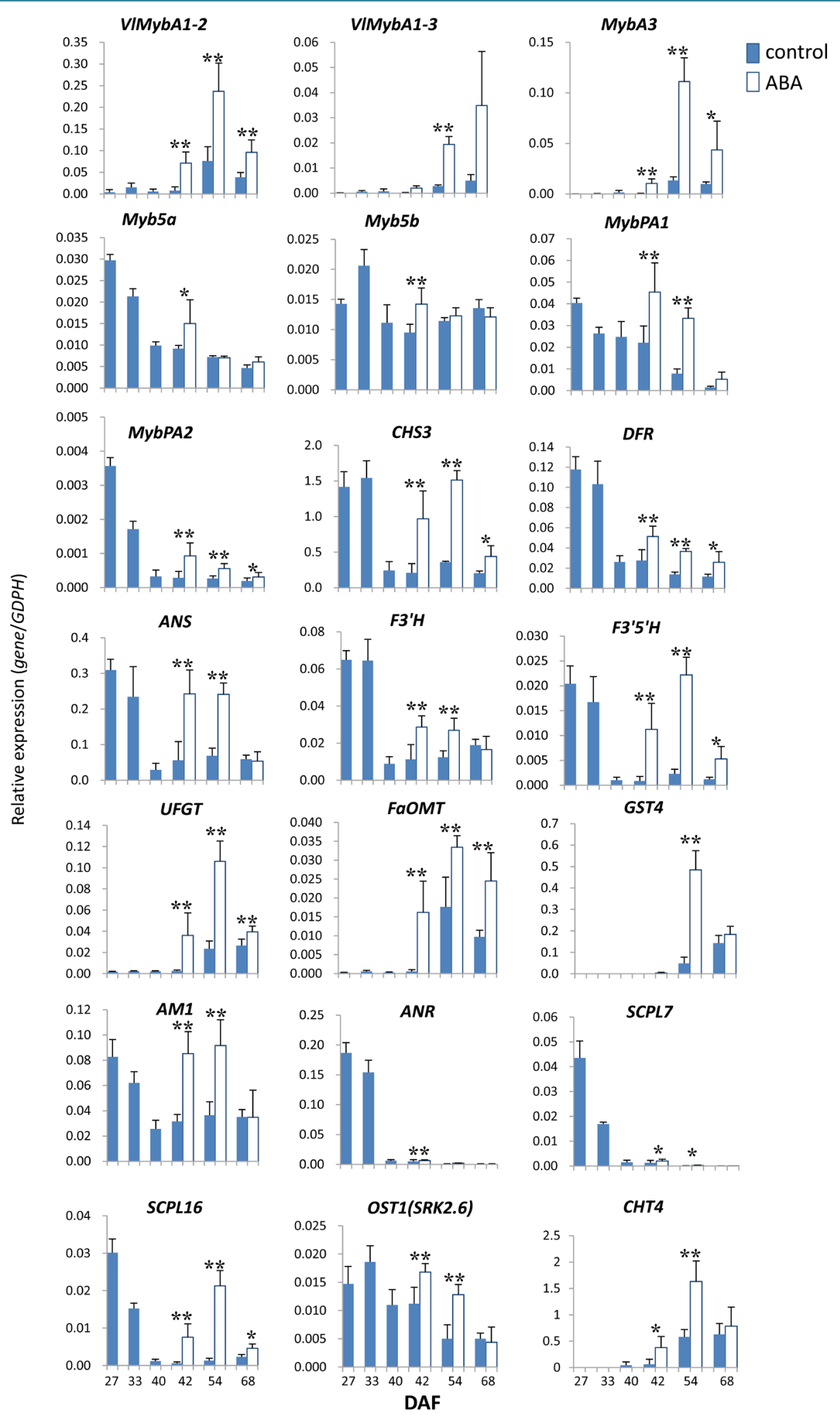

Figure 4. qRT-PCR analysis of genes related to anthocyanin biosynthesis in grape berry skin. In this experiment, samples were treated with $400 \mathrm{ppm} \mathrm{ABA}$ at $39 \mathrm{DAF}$. Expression levels were normalized to that of glyceraldehyde 3-phosphate dehydrogenase $(G A D P H)$. Each bar represents the mean value \pm SD of three replicates. Bars labelled with asterisks indicate significant differences with respect to untreated berry skin samples. ${ }^{* *} P<0.01,{ }^{*} P<0.05$ (Student's $t$-test). 
VlMybA1-3, and MybA3 levels at 42 DAF were increased by 8.7, 13.9, and 32.1 fold, respectively, relative to those in untreated berry skin, but decreased to 3.1, 6.8, and 8.3 times the control values, respectively, at 54 DAF.

\subsection{Anthocyanin Biosynthetic Enzyme Genes Show Variable Patterns of Expression during Berry Development That Are Altered by ABA Treatment}

Among the 12 structural genes examined, four [UFGT, FaOMT, GST4, and anthoMATE1 (AM1)] are involved in anthocyanin biosynthesis and transport, three [ANR, serine carboxypeptidase-like acyltransferase (SCPL)7, and SCPL16] are implicated in the formation of proanthocyanidin, and the remaining five [CHS3, dihydroflavonol reductase (DFR), anthocyanidin reductase (ANS), flavonoid 3'hydroxylase $\left(F 3^{\prime} H\right)$, and $\left.F 3^{\prime} 5^{\prime} H\right]$ function in a common flavonoid biosynthesis pathway (Figure 1). The expression kinetics in control and ABA-treated berry skin followed three distinct patterns. The levels of UFGT and FaOMT were upregulated in control berry skin about 2 weeks after véraison (at 54 DAF; Figure 4). ABA treatment increased their expression to 14.4 and 27.6 times those in untreated berry skin, respectively, within 3 days (at $42 \mathrm{DAF}$ ) and the magnitudes of increase gradually decreased thereafter (to 4.5 and 1.9 times higher than control, respectively, at 54 DAF). These expression kinetics were similar to those described above for $\mathrm{CHT} 4$.

GST4 expression was similar to that of UFGT, FaOMT, and CHT4, but was undetectable in control berry skin until 42 DAF. Therefore, the effect of ABA treatment was first detected at 54 DAF, at which time the level of GST4 was 10.1 times higher than in untreated berry skins, and then decreased to levels in untreated berry skin at 68 DAF.

The other nine genes-i.e., CHS3, DFR, ANS, F3'H, F3'5'H, AM1, ANR, SCPL7, and SCPL16-showed similar expression patterns. The expression of these genes in control berry skin was higher before (at 27 and 33 $\mathrm{DAF}$ ) and decreased after véraison (Figure 4). ABA treatment increased the expression levels to varying degrees; the kinetics were similar to those described above for OST1. It is worth noting that F3' $H$ and $F 3^{\prime}{ }^{\prime}{ }^{\prime} H-$ whose products act antagonistically in flavonoid biosynthesis-showed varied response to ABA treatment (Figure 1). The expression of F3'5'H increased by 13.0 and 9.6 folds upon ABA treatment at 42 DAF and 54 DAF, while the expression of F3'H increased by 2.5 and 2.2 folds, respectively.

\section{Discussion}

Application of a plant growth regulator is one strategy for controlling skin color development in grape berries, and viticulturists have sought to establish ABA-based method for enhancing the red color of table and wine grapes. In our results, ABA treatment at a higher concentration $(400 \mathrm{ppm})$ increased total anthocyanin content while decreasing TSS. Treatment at a lower concentration (200 ppm) late in the growing season (55 DAF) increased the total anthocyanin content by 3.8 fold without decreasing TSS. These results indicate that ABA treatment around véraison negatively affects the sugar accumulation of "Aki Queen” berries, while the treatment at later maturation stage can enhance coloration without the decrease of TSS (including unpublished data).

Anthocyanin group composition in grape berry skin was altered by ABA treatment around véraison; the concentrations of petunidin and malvidin (dark blue/purple color) were increased, which resulted the decreased composition of cyanidin and peonidin (red color). The former two and the latter two anthocyanins are synthesized by $F 3^{\prime}{ }^{\prime}{ }^{\prime} H$ and $F 3^{\prime} H$, respectively, which were enzymes that functioned antagonistically (Figure 1). Consistent with these changes F3'5' $H$ expression was increased to a greater extent than that of $F 3^{\prime} H$ by ABA treatment (13 vs. 2.5 times the level in untreated berry skin). Similar results were obtained in a previous study [2] that reported not only an increase in total anthocyanin content but also a change in the composition ratios of various anthocyanins in "Aki Queen" berries (i.e., increases in petunidin and malvidin types and decreases in peonidin and cyanidin types). On the contrary, others had shown that ABA treatment did not influence anthocyanin composition in "Aki Queen" and "Pinot Noir" grape berry skin [32] [33]. These contradictory results may be due to the presence of seeds in the berries, since the latter studies do not employ treatment for seedless; it is well known that berry ripening is affected by the presence or absence of seeds [34] [35]. In this context, it is worth noting that exogenous ABA treatment modifies total anthocyanin concentration and anthocyanin composition in "Crimson Seedless" grape berries [36].

In this work, two genes were used as reporters for ABA response. CHT4 was identified as an ABA-inducible gene by a gene chip analysis using berry skin from the "Cabernet Sauvignon" [30], while OST1 was identified as a low temperature-inducible gene by oligo-DNA microarray analysis using detached "Pione" berries [30]. The 
two genes showed distinct expression kinetics; i.e., in control berry skin, CHT4 expression was upregulated after véraison within 3 days, and was significantly increased by ABA treatment, whereas OST1 expression was higher before véraison and then decreased, and was slightly increased by ABA treatment. Given that OST1 expression was upregulated by low temperature and ABA levels were higher in low temperature-treated grape berries, it was concluded that OST1 was involved in flavonoid biosynthesis in berry skin via low temperature-induced ABA signaling [30]. The Arabidopsis OST1 ortholog encoded an ABA-activated protein kinase, but ABA treatment had no detectable effect on OST1 mRNA abundance or on OST1 promoter-reporter activity, indicating that Arabidopsis OST1 expression was not directly regulated by ABA [37]. It is therefore likely that expression of the grape OST1 gene is associated with berry ripening and is not directly regulated by ABA; instead, some signal induced by its application might indirectly increase OST1 expression.

The expression kinetics of flavonoid biosynthesis-related genes examined in the present study was similar to those of either CHT4 or OST1. The former group included the Myb-related transcription factor genes VIMybA1-2, VIMybA1-3, and MybA3 and the structural genes UFGT, FaOMT, and GST4. The three Myb genes are contiguously clustered on chromosome 2, although MybA3 is considered as a pseudogene [4] [7]. In grapes, MybA1s regulate the anthocyanin synthesis pathway [4]-[7]. ABA has been reported to induce increases in VvmybA1 mRNA levels [25] [30], strongly supporting our conclusion that the expression of genes in this group is directly modulated by ABA. UFGT encodes a key enzyme that mediates carbon flow to anthocyanins in grapes [38] [39]; FaOMT encodes an OMT involved in anthocyanin methylation [40]; and GST4 encodes a non-enzymatic carrier involved in the transport and storage of anthocyanins in vacuoles [17]. UFGT, OMT, and GST have been implicated in grape berry coloration [40] [41], and their expression was increased in transgenic grapevines ectopically expressing the VvmybA1-2 gene [42]. These reports, together with our results, clearly indicate that ABA treatment induces the upregulation of genes encoding transcription factors as well as structural components involved in anthocyanin biosynthesis, leading to the accumulation of anthocyanin in berry skin.

Genes with OST1-type kinetics included four Myb-related transcription factor genes (Myb5a, Myb5b, Myb$P A 1$, and MybPA2) and nine structural genes (CHS3, DFR, ANS, F3'H, F3', 5'H, AM1, ANR, SCPL7, and SCPL16). Of these, Myb5a, Myb5b, CHS3, F3' $H, F 3^{\prime}, 5^{\prime} H, D F R$, and ANS are involved in the general flavonoid biosynthesis pathway [9] [10] [14] [43] whereas MybPA1, MybPA2, and ANR are associated with the proanthocyanidin pathway [11]-[13] [16] [44]. SCPL7 and SCPL16 are orthologs of DkSCPL1 and DkSCPL2, which have been linked to proanthocyanidin accumulation in persimmon fruit [45] [46]. AM1 encodes a multidrug and toxic compound extrusion family transporter that is thought to be involved in anthocyanin transport to vacuoles [18]; however, we found that it was expressed at higher levels before véraison when there was no anthocyanin accumulation, suggesting that AM1 may also function in the transport of flavonoids other than anthocyanins. As discussed above, the expression of OST1-type genes in berries that were not treated with ABA was associated with berry ripening, with some signal stimulated by ABA treatment potentially enhancing the expression of these genes via an indirect mechanism. It was previously reported that ABA treatment of very young berries (at 14 or 17 DAF; 53 and 46 days before véraison) increased the expression of $V v M y b 5 a$, VvMybPA1, and VvANR genes [14] [47]. Since we applied ABA at a later stage (3 days before véraison), our results suggest that the effects of ABA on the expression of these genes depend on the timing of treatment. Interestingly, the levels of $A N R$ - which encodes a key enzyme modulating carbon flow to proanthocyanidin — and SCPL7 were drastically reduced at véraison and remained extremely low even with ABA treatment, while the expression of other OST1-type genes were increased to a level comparable to those observed before véraison in response to ABA treatment. These results imply the influence of a factor(s) other than ABA on the regulation of flavonoid-especially proanthocyanidin-biosynthesis.

In conclusion, ABA treatment around véraison significantly increased the amount of petunidin- and malvidin-type anthocyanins, which resulted in deep coloration of berry skin. The changes were mainly caused by ABA-induced upregulation of UFGT, GST4, FaOMT and $F 3^{\prime}{ }^{\prime}{ }^{\prime} H$, and also by a hitherto unknown regulation system governing the gene expression of proanthocyanidin biosynthesis. ABA treatment to other red grape varieties on late maturation stage also increased anthocyanin content and improved berry coloration without decrease of TSS (manuscript in preparation). These results indicate that ABA treatment a few weeks before harvest can lead to the production of berries with the desired color.

\section{Acknowledgements}

This work was supported in part by Grants-in-Aid for Young Scientists (nos. 21880041 and 22780029) from the 
Ministry of Education, Culture, Sports, Science, and Technology of Japan, and by a Grant for the Promotion of Research from Actree Corporation. The authors wish to thank Dr. T. Akagi (Kyoto University, Kyoto, Japan) for providing the sequence information of VvSCPL7 and VvSCPL16.

\section{References}

[1] Falginella, L., Gaspero, G.D. and Castellarin, S.D. (2012) Expression of Flavonoid Genes in the Red Grape Berry of "Alicante Bouschet" Varies with the Histological Distribution of Anthocyanins and Their Chemical Composition. Planta, 236, 1037-1051. http://dx.doi.org/10.1007/s00425-012-1658-2

[2] Kitamura, H., Nakayama, M., Nishikawa, Y., Kondou, H., Koshita, M. and Hiratsuka, S. (2005) Relationship between the Deep Coloration and Anthocyanins in the Skin of “Aki Queen” Berries. Journal of the Japanese Society for Horticultural Science, 75, 401-406. http://dx.doi.org/10.2503/jjshs.74.401

[3] Shiraishi, S., Watanabe, Y., Okubo, H. and Uemoto, S. (1986) Anthocyanin Pigments of Black-Purple Grapes Related to Variety "Kyoho” (Vitis vinifera L. × V. labrusca L.). Journal of the Japanese Society for Horticultural Science, 55, 123-129. http://dx.doi.org/10.2503/jjshs.55.123

[4] Azuma, A., Kobayashi, S., Mitani, N., Shiraishi, M., Yamada, M., Ueno, T., Kono, A., Yakushiji, H. and Koshita, Y. (2008) Genomic and Genetic Analysis of Myb-Related Genes That Regulate Anthocyanin Biosynthesis in Grape Berry Skin. Theoretical and Applied Genetics, 117, 1009-1019. http://dx.doi.org/10.1007/s00122-008-0840-1

[5] Kobayashi, S., Goto-Yamamoto, N. and Hirochika H. (2004) Retrotransposon-Induced Mutations in Grape Skin Color. Science, 304, 982. http://dx.doi.org/10.1126/science.1095011

[6] Kobayashi, S., Goto-Yamamoto, N. and Hirochika, H. (2005) Association of VvMybA1 Gene Expression with Anthocyanin Production in Grape (Vitis vinifera) Skin-Color Mutants. Journal of the Japanese Society for Horticultural Science, 74, 196-203. http://dx.doi.org/10.2503/jjshs.74.196

[7] Walker, A.R., Lee, E., Bogs, J., McDavid, D.A.J., Thomas, M.R. and Robinson, S.P. (2007) White Grapes Arose through the Mutation of Two Similar and Adjacent Regulatory Genes. Plant Journal, 49, 772-785. http://dx.doi.org/10.1111/j.1365-313X.2006.02997.x

[8] Cavallini, E., Zenoni, S., Finezzo, L., Guzzo, F., Zamboni, A., Avesani, L. and Tornielli G.B. (2014) Functional Diversification of Grapevine MYB5a and MYB5b in the Control of Flavonoid Biosynthesis in a Petunia Anthocyanin Regulatory Mutant. Plant Cell Physiology, 55, 517-534. http://dx.doi.org/10.1093/pcp/pct190

[9] Deluc, L., Barrieu, F., Marchive, C., Lauvergeat, V., Decendit, A., Richard, T., Carde, J.P., Mérillon, J.M. and Hamdi, S. (2006) Characterization of a Grapevine R2R3-MYB Transcription Factor That Regulates the Phenylpropanoid Pathway. Plant Physiology, 140, 499-511. http://dx.doi.org/10.1104/pp.105.067231

[10] Deluc, L., Bogs, J., Walker, A.R., Ferrier, T., Decendit, A., Mérillon, J.M., Robinson, S.P. and Barrieu, F. (2008) The Transcription Factor VvMYB5b Contributes to the Regulation of Anthocyanin and Proanthocyanin Biosynthesis in Developing Grape Berries. Plant Physiology, 147, 2041-2053. http://dx.doi.org/10.1104/pp.108.118919

[11] Bogs, J., Ebadi, A., McDavid, D. and Robinson S.P. (2006) Identification of the Flavonid Hydroxylases from Grapevine and Their Regulation during Fruit Development. Plant Physiology, 140, 279-291. http://dx.doi.org/10.1104/pp.105.073262

[12] Bogs, J., Jaffé, F.W., Takos, A.M., Walker, A.R. and Robinson S.P. (2007) The Grapevine Transcription Factor VvMYBPA1 Regulates Proanthocyanidin Synthesis during Fruit Development. Plant Physiology, 143, 1347-1361. http://dx.doi.org/10.1104/pp.106.093203

[13] Terrier, N., Torregrosa, L., Ageorges, A., Vialet, S., Verriès, C., Cheynier, V. and Romieu, C. (2009) Ectopic Expression of VvMybPA2 Promotes Proanthocyanidin Biosynthesis in Grapevine and Suggests Additional Targets in the Pathway. Plant Physiolgy, 149, 1028-1041. http://dx.doi.org/10.1104/pp.108.131862

[14] Koyama, K., Numata, M., Nakajima, I., Goto-Yamamoto, N., Matsumura, H. and Tanaka, N. (2014) Functional Characterization of a New Grapevine MYB Transcription Factor and Regulation of Proanthocyanidin Biosynthesis in Grapes. Journal of Experimental Botany, 65, 4433-4449. http://dx.doi.org/10.1093/jxb/eru213

[15] Czemmel, S., Stracke, R., Weisshaar, B., Cordon, N., Harris, N.N., Walker, A.R., Robinson, S.P. and Bogs, J. (2009) The Grapevine R2R3-MYB Transcription Factor VvMYBF1 Regulates Flavonol Synthesis in Developing Grape Berries. Plant Physiology, 151, 1513-1530. http://dx.doi.org/10.1104/pp.109.142059

[16] Xie, D.Y., Sharma, S.B., Paiva, N.L., Ferreira, D. and Dixon, R.A. (2003) Role of Anthocyanidin Reductase, Encoded by BANYULS in Plant Flavonoid Biosynthesis. Science, 229, 396-399. http://dx.doi.org/10.1126/science.1078540

[17] Conn, S., Curtin, C., Bézier, A., Franco, C. and Zhang, W. (2008) Purification, Molecular Cloning, and Characterization of Glutathione S-Transferases (GSTs) from Pigmented Vitis vinifera L. Cell Suspension Cultures as Putative Anthocyanin Transport Proteins. Journal of Experimental Botany, 59, 3621-3634. http://dx.doi.org/10.1093/jxb/ern217 
[18] Gomez, C., Terrier, N., Torregrosa, L., Vialet, S., Fournier-Level, A., Verriès, C., Souquet, J.M., Mazauric, J.P., Klein, M., Cheynier, V. and Ageorges, A. (2009) Grapevine MATE-Type Proteins Act as Vacuolar $\mathrm{H}^{+}$-Dependent Acylated Anthocyanin Transporters. Plant Physiology, 150, 402-415. http://dx.doi.org/10.1104/pp.109.135624

[19] Gomez, C., Conejero, G., Torregrosa, L., Cheynier, V., Terrier, N. and Ageorges, A. (2011) In Vivo Grapevine Anthocyanin Transport Involves Vesicle-Mediated Trafficking and the Contribution of anthoMATE Transporters and GST. The Plant Journal, 67, 960-970. http://dx.doi.org/10.1111/j.1365-313X.2011.04648.x

[20] He, F., Mu, L., Yan, G.L., Liang, N.N., Pan, Q.H., Wang, J., Reeves, M.J. and Duan, C.Q. (2010) Biosynthesis of Anthocyanins and Their Regulation in Colored Grapes. Molecules, 15, 9057-9091. http://dx.doi.org/10.3390/molecules15129057

[21] Kuhn, N., Guan, L., Dai, Z.W., Wu, B.H., Lauvergeat, V., Gomès, E., Li, S.H., Godoy, F., Arce-Johnson, P. and Delrot, S. (2014) Berry Ripening: Recently Heard through the Grapevine. Journal of Experimental Botany, 65, 4543-4559. http://dx.doi.org/10.1093/jxb/ert395

[22] Coombe, B.G. and Hale, C.R. (1973) The Hormone Content of Ripening Grape Berries and the Effect of Growth Substance Treatments. Plant Physiology, 51, 629-634. http://dx.doi.org/10.1104/pp.51.4.629

[23] Sun, L., Zhang, M., Ren, J., Qi, J., Zhang, G. and Leng, P. (2010) Reciprocity between Abscisic Acid and Ethylene at the Onset of Berry Ripening and after Harvest. BMC Plant Biology, 10, 257. http://dx.doi.org/10.1186/1471-2229-10-257

[24] Ban, T., Ishimaru, M., Kobayashi, S., Goto-Yamamoto, N. and Horiuchi, S. (2003) Abscisic Acid and 2,4-Dichlorophenoxyacetic Acid Affect the Expression of Anthocyanin Biosynthetic Pathway Genes in 'Kyoho' Grape Berries. The Journal of Horticultural Science \& Biotechnology, 78, 586-589. http://dx.doi.org/10.1080/14620316.2003.11511668

[25] Jeong, S.T., Goto-Yamamoto, N., Kobayashi, S. and Esaka, M. (2004) Effects of Plant Hormones and Shading on the Accumulation of Anthocyanins and the Expression of Anthocyanins Biosynthetic Genes in Grape Berry Skins. Plant Science, 167, 247-252. http://dx.doi.org/10.1016/j.plantsci.2004.03.021

[26] Gagné, S., Cluzet, S., Mérillon, J.-M. and Gény, L. (2011) ABA Initiates Anthocyanin Production in Grape Cell Cultures. Journal of Plant Growth Regulation, 30, 1-10. http://dx.doi.org/10.1007/s00344-010-9165-9

[27] Hiratsuka, S., Onodera, H., Kawai, Y., Kubo, T., Itoh, H. and Wada, R. (2001) ABA and Sugar Effects on Anthocyanin Formation in Grape Berry Cultured in Vitro. Scientia Horticulturae, 90, 121-130. http://dx.doi.org/10.1016/S0304-4238(00)00264-8

[28] Shiraishi, M., Yamada, M., Mitani, N. and Ueno, T. (2007) A Rapid Determination Method for Anthocyanin Profiling in Grape Genetic Resources. Journal of the Japanese Society for Horticultural Science, 76, 28-35. http://dx.doi.org/10.2503/jjshs.76.28

[29] Wan, C.Y. and Wilkins, T.A. (1994) A Modified Hot Borate Method Significantly Enhances the Yield of High-Quality RNA from Cotton (Gossypium hirsutum L.). Analytical Biochemistry, 223, 7-12. http://dx.doi.org/10.1006/abio.1994.1538

[30] Azuma, A., Fujii, H., Shimada, T. and Yakushiji, H. (2015) Microarray Analysis for the Screening of Genes Inducible by Light or Low Temperature in Post-Veraison Grape Berries. The Horticulture Journal, 84, 214-226. http://dx.doi.org/10.2503/hortj.MI-041

[31] Koyama, K., Sadamatsu, K. and Goto-Yamamoto, N. (2010) Abscisic Acid Stimulated Ripening and Gene Expression in Berry Skins of the Cabernet Sauvignon Grape. Functional \& Integrative Genomics, 10, 367-381. http://dx.doi.org/10.1007/s10142-009-0145-8

[32] Mori, K., Saito, H., Goto-Yamamoto, N., Kitayama, M., Kobayashi, S., Sugaya, S., Gemma, H. and Hashizume, K. (2005) Effects of Abscisic Acid Treatment and Night Temperatures on Anthocyanin Composition in Pinot Noir Grapes. Vitis, 44, 161-165.

[33] Kitamura, H., Nakayama, M., Kondou, H., Nishikawa, Y., Koshita, M. and Hiratsuka, S. (2007) Effect of Abscisic Acid Treatment at Variable Stages on the Expression of Proper and Deep Color in 'Aki Queen' Grape Berry Skins. Horticultural Research (Japan), 6, 271-275. http://dx.doi.org/10.2503/hrj.6.271

[34] Niimi, Y., Ohkawa, M. and Torikata, H. (1977) Changes in Auxin and Abscisic Acid-Like Activities in Grape Berries. Journal of the Japanese Society for Horticultural Science, 46, 139-144. http://dx.doi.org/10.2503/jishs.46.139

[35] Kataoka, I., Sugiura, A., Utsunomiya, N. and Tomana, T. (1982) Effect of Abscisic Acid and Defoliation on Anthocyanin Accumulation in Kyoho Grapes (Vitis vinifera L. $\times$ V. labruscana BAILEY). Vitis, 21, 325-332.

[36] Ferrara, G., Mazzeo, A., Matarrese, A.M.S., Pacucci, C., Punzi, R., Faccia, M., Trani, A. and Gambacorta, G. (2015) Application of Abscisic Acid (S-ABA) and Sucrose to Improve Color, Anthocyanin Content and Antioxidant Activity of cv. Crimson Seedless Grape Berries. Australian Journal of Grape and Wine Research, 21, 18-29. http://dx.doi.org/10.1111/ajgw.12112 
[37] Mustilli, A.C., Merlot, S., Vavasseur, A., Fenzi, F. and Giraudat, J. (2002) Arabidopsis OST1 Protein Kinase Mediates the Regulation of Stomatal Aperture by Abscisic Acid and Acts Upstream of Reactive Oxygen Species Production. The Plant Cell, 14, 3089-3099. http://dx.doi.org/10.1105/tpc.007906

[38] Boss, P.K., Davies, C. and Robinson, S.P. (1996) Expression of Anthocyanin Biosynthesis Pathway Genes in Red and White Grapes. Plant Molecular Biology, 32, 565-569. http://dx.doi.org/10.1007/BF00019111

[39] Boss, P.K., Davies, C. and Robinson, S.P. (1996) Anthocyanin Composition and Anthocyanin Pathway Gene Expression in Grapevine Sports Differing in Berry Skin Color. Australian Journal of Grape and Wine Research, 2, 163-170. http://dx.doi.org/10.1111/j.1755-0238.1996.tb00104.x

[40] Castellarin, S.D., Matthews, M.A., Di Gaspero, G. and Gambetta, G.A. (2007) Water Deficits Accelerate Ripening and Induce Changes in Gene Expression Regulating Flavonoid Biosynthesis in Grape Berries. Planta, 227, 101-112. http://dx.doi.org/10.1007/s00425-007-0598-8

[41] Ageorges, A., Fernandez, L., Vialet, S., Merdinoglu, D., Terrier, N. and Romieu, C. (2006) Four Specific Isogenes of the Anthocyanin Metabolic Pathway Are Systematically Co-Expressed with the Red Color of Grape Berries. Plant Science, 170, 372-383. http://dx.doi.org/10.1016/j.plantsci.2005.09.007

[42] Cutanda-Perez, M.C., Ageorges, A., Gomez, C., Vialet, S., Terrier, N., Romieu, C. and Torregrosa, L. (2009) Ectopic Expression of VlmybA1 in Grapevine Activates a Narrow Set of Genes Involved in Anthocyanin Synthesis and Transport. Plant Molecular Biology, 69, 633-648. http://dx.doi.org/10.1007/s11103-008-9446-x

[43] Czemmel, S., Heppel, S. and Bogs, J. (2012) R2R3 MYB Transcription Factors: Key Regulators of the Flavonoid Biosynthetic Pathway in Grapevine. Protoplasma, 249, S109-S118. http://dx.doi.org/10.1007/s00709-012-0380-z

[44] Bogs, J., Downey, M.O., Harvey, J.S., Ashton, A.R., Tanner, G.J. and Robinson, S.P. (2005) Proanthocyanidin Synthesis and Expression of Genes Encoding Leucoanthocyanidin Reductase and Anthocyanidin Reductase in Developing Grape Berries and Grapevine Leaves. Plant Physiology, 139, 652-663. http://dx.doi.org/10.1104/pp.105.064238

[45] Akagi, T., Ikegami, A., Suzuki, Y., Yoshida, J., Yamada, M., Sato, A. and Yonemori, K. (2009) Expression Balances of Structural Genes in Shikimate and Flavonoid Biosynthesis Causes a Difference in Proanthocyanidin Accumulation in Persimmon (Diospyros kaki Thunb.) Fruit. Planta, 230, 899-915. http://dx.doi.org/10.1007/s00425-009-0991-6

[46] Ikegami, A., Eguchi, S., Kitajima, A., Inoue, K. and Yonemori, K. (2007) Identification of Genes Involved in Proanthocyanidin Biosynthesis of Persimmon (Diospyros kaki) Fruit. Plant Science, 172, 1037-1047. http://dx.doi.org/10.1016/j.plantsci.2007.02.010

[47] Lacampagne, S., Gagné, S. and Gény, L. (2010) Involvement of Abscisic Acid in Controlling the Proanthocyanidin Biosynthesis Pathway in Grape Skin: New Elements Regarding the Regulation of Tannin Composition and Leucoanthocyanidin Reductase (LAR) and Anthocyanidin Reductase (ANR) Activities and Expression. Journal of Plant Growth Regulation, 29, 81-90. http://dx.doi.org/10.1007/s00344-009-9115-6

\section{Submit or recommend next manuscript to SCIRP and we will provide best service for you:}

Accepting pre-submission inquiries through Email, Facebook, Linkedin, Twitter, etc A wide selection of journals (inclusive of 9 subjects, more than 200 journals)

Providing a 24-hour high-quality service User-friendly online submission system Fair and swift peer-review system Efficient typesetting and proofreading procedure Display of the result of downloads and visits, as well as the number of cited articles Maximum dissemination of your research work

Submit your manuscript at: http://papersubmission.scirp.org/ 